OPEN ACCESS

Edited by:

Nahid Ali,

Indian Institute of Chemical Biology

(CSIR), India

Reviewed by:

Maria Agallou,

Pasteur Hellenic Institute, Greece

Sima Rafati,

Pasteur Institute of Iran (PII), Iran

*Correspondence:

Sreenivas Gannavaram sreenivas.gannavaram@fda.hhs.gov Hira L. Nakhasi

hira.nakhasi@fda.hhs.gov

†These authors have contributed equally to this work

Specialty section

This article was submitted to Vaccines and Molecular Therapeutics, a section of the journal

Frontiers in Immunology

Received: 28 June 2019 Accepted: 09 September 2019

Published: 24 September 2019

Citation:

Gannavaram S, Bhattacharya P, Siddiqui A, Ismail N, Madhavan S and Nakhasi HL (2019) miR-21 Expression Determines the Early Vaccine Immunity Induced by LdCen $^{-/-}$Immunization.

Front. Immunol. 10:2273. doi: 10.3389/fimmu.2019.02273

\section{miR-21 Expression Determines the Early Vaccine Immunity Induced by LdCen-/- Immunization}

\author{
Sreenivas Gannavaram ${ }^{1 \star t}$, Parna Bhattacharya ${ }^{1+}$, Abid Siddiqui ${ }^{1}$, Nevien Ismail ${ }^{1}$, \\ Subha Madhavan ${ }^{2}$ and Hira L. Nakhasi ${ }^{1 *}$
}

${ }^{1}$ Division of Emerging and Transfusion Transmitted Diseases, Center for Biologics Evaluation and Research, US Food and Drug Administration, Silver Spring, MD, United States, ${ }^{2}$ Innovation Center for Biomedical Informatics, Georgetown University, Washington, DC, United States

No vaccine exists against visceral leishmaniasis. Toward developing vaccines against $\mathrm{VL}$, we have reported previously on the immunogenicity of live attenuated $L d C e n^{-1-}$ parasites in animal models. Immunization with $\mathrm{LdCen}^{-/-}$parasites has been shown to induce durable protective immunity in pre-clinical animal models. Although the innate immune responses favoring a Th1 type immunity are produced following $\mathrm{LdCen}^{-/-}$ immunization, the molecular determinants of such responses remain unknown. To identify early biomarkers of immunogenicity associated with live attenuated parasitic vaccines, we infected macrophages derived from healthy human blood donors with $L d C e n^{-/}$or LdWT parasites ex vivo and compared the early gene expression profiles. In addition to altered expression of immune related genes, we identified several microRNAs that regulate important cytokine genes, significantly altered in $\mathrm{LdCen}^{-1-}$ infection compared to $L d W T$ infection. Importantly, we found that $L d C e n^{-/-}$infection suppresses the expression of microRNA-21 (miR-21) in human macrophages, which negatively regulates IL12, compared to LdWT infection. In murine DC experiments, LdCen ${ }^{-/}$infection showed a reduced miR-21 expression with a concomitant induction of IL12. Silencing of miR-21 using specific inhibitors resulted in an augmented induction of IL12 in LdWT infected BMDCs, illustrating the role of miR-21 in LdWT mediated suppression of IL12. Further, exosomes isolated from $L d C e n^{-1-}$ infected DCs contained significantly reduced levels of miR-21 compared to $L d W T$ infection, that promoted proliferation of $C D 4^{+} \mathrm{T}$ cells in vitro. Similar miR-21 mediated IL12 regulation was also observed in ex vivo human macrophage infection experiments indicating that miR-21 plays a role in early IL12 mediated immunity. Our studies demonstrate that $\mathrm{LdCen}^{-1-}$ infection suppresses miR-21 expression, enables IL12 mediated induction of adaptive immunity including proliferation of antigen experienced $\mathrm{CD}^{+}{ }^{+} \mathrm{T}$ cells and development of a Th1 immunity, and suggest that miR-21 could be an important biomarker for $L_{d C e n^{-/}}$vaccine immunity in human clinical trials.

\section{ONE SENTENCE SUMMARY}

Role of miR-21 in vaccine induced immunity.

Keywords: leishmaniasis, microRNA, miR-21, IL-12, live attenuated Leishmania vaccines, biomarker, parasitic vaccines 


\section{INTRODUCTION}

Leishmaniasis, caused by the protozoan parasites Leishmania, is a neglected protozoan disease that mainly affects the tropical as well as subtropical countries of the world. Annually, 200,000-400,000 new cases of visceral leishmaniasis (VL) are reported that results in 20,000-40,000 deaths with $95 \%$ of the fatal cases occurring in six countries, namely, India, Bangladesh, Sudan, Nepal, Ethiopia, and Brazil (1). Globally, 0.7-1.2 million new cases of cutaneous leishmaniasis (CL) occur every year (2). Despite the recent advances in antileishmanial chemotherapeutics, eradication of the disease by chemotherapy alone is not possible (3). Since Leishmaniasis is a disease of the poor occurring mostly in remote rural villages with poor housing and little access to modern health-care, chemotherapy may be inadequate (4). Currently, there are no FDA-licensed vaccines or screening tests for Leishmania parasites in the US. Immigration to US from Latin American, African, and Middle Eastern countries, areas with high incidence of Leishmaniasis, is increasing. Although most of the cases of leishmaniasis diagnosed in the United States are in people who became infected while traveling or living in other countries, autochthonous cases of cutaneous leishmaniasis are reported in southern United States [https://www.cdc.gov/parasites/leishmaniasis/gen_ info/faqs.html, (5)]. These factors pose a serious risk of spread of the disease in the US by these blood-borne pathogens. Prevalence of canine leishmaniasis and reports of vector transmission of Leishmania parasites in southern United States further highlight the potential for widespread dissemination (6). Therefore, there is an urgent need for developing effective vaccines against human leishmaniasis.

We have reported previously on the protective efficacy induced by centrin gene deleted Leishmania donovani parasites $\left(\mathrm{LdCen}^{-/-}\right)$as live attenuated vaccines $(7-10)$. The protective immunity induced by $\mathrm{LdCen}^{-/-}$parasites was mediated by strong multifunctional $\mathrm{CD}^{+}$and $\mathrm{CD}^{+} \mathrm{T}$ cell responses (8). Further studies showed that immunization with $\mathrm{LdCen}^{-/-}$ parasites induces strong pro-inflammatory response including IL-12, IFN- $\gamma$, IL-17, and reduced IL-10 production from macrophages compared to virulent wild type $L$. donovani $(\operatorname{LdWT})$ infection $(11,12)$. Studies showed that following immunization, $\mathrm{LdCen}^{-/-}$parasites alter the early innate immune response including programming of parasitized macrophages to M1 type, increased expression of co-stimulatory signals, subdued co-inhibitory signals on the parasitized dendritic cells, and secretion of pro-inflammatory cytokines compared to virulent parasite infection (13). However, the molecular determinants of early innate immune responses following immunization remain to be determined. Identification of the molecular determinants of early immune response not only reveals the immune mechanisms important for protective immunity but also lead to biomarkers of protection that would aid in advancing the vaccines toward clinical studies and regulatory approvals.

MicroRNAs (miRNAs) are noncoding ssRNAs of 19-25 nucleotide in length that mediate post-transcriptional regulation of various target genes $(14,15)$. miRNAs usually bind to sites of nucleotide sequence complementarity in the 3-untranslated region (UTR) of target genes and regulate their gene expression by mechanisms including inhibition of translation, degradation of mRNA (16). miRNAs play critical roles in a broad range of biological processes, including development, stress response, cancer, and cardiac hypertrophy therefore the roles of miRNAs in both normal homeostatic and pathological processes are widely studied $(17,18)$. Due to the important roles played by microRNAs, their role in innate immunity is investigated with great interest $(19,20)$. More specifically miR-21 has been shown to be a negative regulator of IL-12 in allergic inflammation (21). In this study we have determined the microRNAs whose expression is specifically altered following Leishmania infection and investigated the role of miR-21 in the regulation of IL-12 in both murine and ex vivo human infection studies in the context of $\mathrm{LdCen}^{-/-}$immunization.

\section{RESULTS}

\section{Distinct microRNA Expression Profiles Are Induced in Human Macrophages Upon LdCen-/- Infection Compared to LdWT Infection}

To test whether distinct microRNAs are expressed following infection of macrophages with either LdWT or $\mathrm{LdCen}^{-/-}$ parasites replica macrophage cultures from elutriated human monocytes were established. Monocytes were differentiated in vitro into macrophages and infected with $L d W T$ or $L d C e n^{-/-}$ parasites. Replica macrophage cultures were stained with DiffQuik reagent after $24 \mathrm{~h}$ infection. The percentage of infected macrophages and the parasite indices were comparable across all infections and donors (Supplementary Figure 1). The quality of RNA was assessed by a RNA Bioanalyzer and RNAseq was performed on the isolated RNA samples. RNA sequencing revealed distinct microRNA expression profiles in human macrophages upon $\mathrm{LdCen}^{-/-}$infection compared to $L d W T$ infection (Figure 1A, Supplementary Figure 2). We performed a pairwise comparison of the expression of small RNAs between uninfected, $L d W T$ infected, and $L_{d C e n}{ }^{-/-}$infected macrophages. Results indicated that several microRNAs are enriched in $L d W T$ infection compared to $\mathrm{LdCen}^{-/-}$infection in healthy donors ( $p<0.05$, Supplementary Table 1, Figure 1B). Of the several microRNAs that are enriched in $L d W T$ infection compared to $\mathrm{LdCen}{ }^{-/-}$infection, miR-21 was selected for further study due to its role in the regulation of IL-12 expression in recent studies $(21,22)$.

\section{Suppression of miR-21 Expression in LdCen-/- Infected Murine DCs in vitro}

To test whether suppression of miR-21 expression observed in human macrophages due to $\mathrm{LdCen}^{-/-}$infection can be recapitulated in antigen presenting cells in murine models and thus enable understanding of the role of miR-21 in $\mathrm{LdCen}^{-/-}$ induced innate immunity, we first performed in vitro infection experiments with bone marrow derived DCs from C57bl/6 mice. Further DCs have been recognized as the main producer of IL12 following Leishmania infection (23). BMDCs infected with 


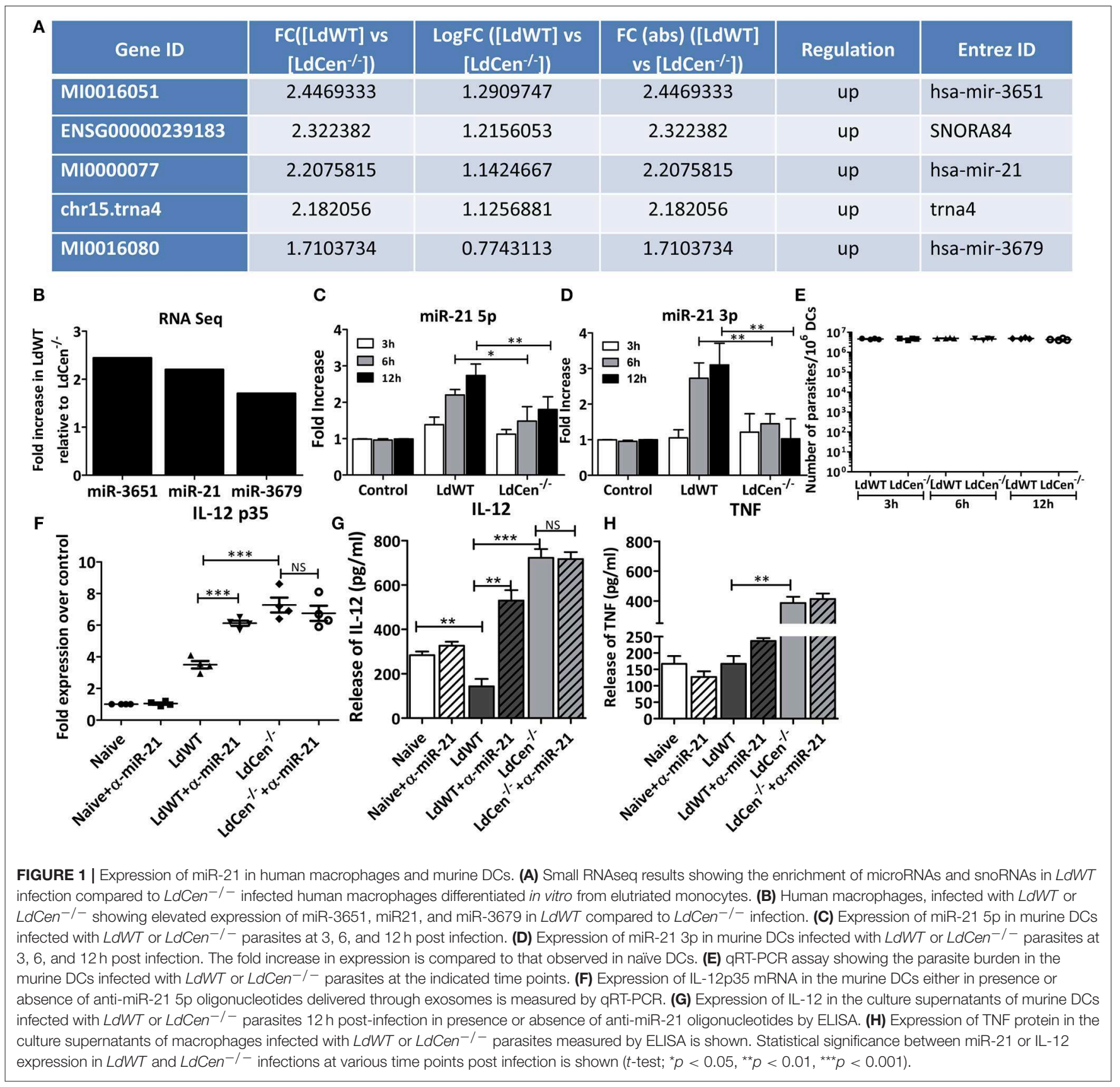

$L d \mathrm{Cen}^{-/}$- parasites induced significantly reduced expression of miR-21 compared to $L d W T^{-}$infection as early as $3 \mathrm{~h}$ post infection (Figure 1C, ${ }^{*} p<0.05,{ }^{* *} p<0.01$ ). High induction of miR-21 $5 \mathrm{p}$ was sustained even at 6 and $12 \mathrm{~h}$ post infection in $L d W T$ infection compared to $L d C e n^{-/-}$infection. Both the isoforms of miR-21 i.e., miR-21 $5 p$ and miR-21 $3 p$ were found to be significantly suppressed in $\mathrm{LdCen}^{-/-}$infection compared to $L d W T$ infection (Figures 1C,D, ${ }^{*} p<0.05$, ** $p$ $<0.01)$. The pre-miRNA hairpin is cleaved by the RNase III enzyme Dicer to generate miRNA-5p and miRNA-3p. Among these the $5 p$ strand is present in the forward $\left(5^{\prime}-3^{\prime}\right)$ position, while the $3 p$ strand is located in the reverse position. RTPCR assay to measure the Leishmania minicircle DNA showed a comparable parasite infection in the DCs in vitro across the time points suggesting that the observed differences in miR-21 levels between $L d W T$ and $\mathrm{LdCen}^{-/-}$are not due to variation in the parasite infection levels (Figure 1E). Since miR21 has been shown to target $3^{\prime}$ UTR of the mRNA encoding IL-12p35 for degradation, we measured the expression of IL12 p35 by qRT-PCR. Results showed that the abundance of IL12 is inversely proportional to miR-21 expression (Figure 1F, *** $p<0.001)$. Further, blocking of miR-21 using anti-sense 
oligonucleotides delivered through murine DC exosomes showed restoration of the IL-12 expression in DCs infected with $L d W T$. No significant difference was observed in IL-12p35 expression in murine DCs upon $\mathrm{LdCen}^{-/-}$infection treated with antimiR-21 oligonucleotides due to low level of mR-21 expression observed in $\mathrm{LdCen}^{-/-}$infection. However, the IL-12 protein levels measured in the culture supernatants showed an increase upon miR-21 inhibition in $L d W T$ infection (Figure 1G, ${ }^{* *} p$ $\left.<0.01,{ }^{* * *} p<0.001\right)$ consistent with the mRNA expression of IL-12 (Figure 1F). We did not observe any significant differences in TNF due to miR-21 inhibition in $L d W T$ or $\mathrm{LdCen}^{-/-}$infections even though significant difference was observed between $L d W T$ and $L d C e n^{-/-}$infections without miR21 inhibition (Figure 1H, ${ }^{* *} p<0.01$ ). Consistent with our previous observations in $L d W T$ and $\mathrm{LdCen}^{-/-}$infections in mice (8), there was a slightly lower but not significant difference in the IL-10 level ( $p=0.135)$. Similarly, a slightly higher but not significant IFN- $\gamma$ level $(p=0.058)$ was observed between $L d W T$ and $L_{d C e n}{ }^{-/-}$. No significant differences were observed between untreated and $\alpha$-miR-21 treated groups in both infection groups suggesting that miR-21 effect is mainly observed in IL-12 expression (Supplementary Figure 2).

\section{In vivo Inhibition of miR-21 Due to LdCen-/- Infection Restores IL-12 Expression}

To further confirm our results from the in vitro DC infection experiments, we performed miR-21 expression analysis in vivo in mice infected with $L d W T$ or $L d C e n^{-1-}$ parasites. Infection with either red fluorescence protein expressing $L d W T\left(L d W T^{R F P}\right)$ or mCherry expressing $\mathrm{LdCen}^{-/-}\left(\mathrm{LdCen}^{-/-m C h e r r y}\right)$ parasites allowed us to isolate APCs infected with parasites from spleen and lymph nodes for analysis by fluorescence-based sorting (Figure 2A). miR-21 expression in parasitized cells was tested at various time points after infection with either $L d W T$ or $\mathrm{LdCen}^{-/-}$parasites. Similar to our in vitro studies, miR-21 expression was found to be reproducibly high in cells infected with $L d W T$ compared to $L d C e n^{-/-}$infection starting from $12 \mathrm{~h}$ post infection to all the time points tested (Figures $2 \mathbf{B}-\mathbf{D},{ }^{*} p$ $\left.<0.05,{ }^{* *} p<0.01,{ }^{* * *} p<0.001\right)$. RT-PCR assay to measure the Leishmania minicircle DNA showed a comparable parasite infection in the parasitized APCs in vivo at 12 and $24 \mathrm{~h}$ time points following infection suggesting that the observed differences in miR-21 levels between $L d W T$ and $\mathrm{LdCen}^{-/}$are not due to variation in the parasite infection level (Figure $2 \mathrm{E}$, ${ }^{*} p$ $<0.05)$. As expected, the number of $\mathrm{LdCen}^{-/-}$parasites showed a decline at the $72 \mathrm{~h}$ time point due to the limited replication as a result of deletion of centrin gene in these parasites (Figure 2E, $\left.{ }^{*} p<0.05\right)$. Of interest, we found that miR-21 expression was also altered in non-infected i.e., bystander cells. The bystander cells also showed high expression of miR-21 compared to uninfected controls although it was significantly less than that observed in the parasitized cells at all the time points tested (Figures 2B-D). LdCen ${ }^{-/}$infection induced consistently less miR-21 compared to $L d W T$ infection at all time points tested in parasitized and bystander cells (Figures 2B-D). Measurements of IL-12 mRNA in the parasitized cells showed a reproducible higher expression in $\mathrm{LdCen}^{-/-}$infection compared to $\mathrm{LdWT}$ infection, consistent with our in vitro results (Figure $2 \mathrm{~F},{ }^{* * *} p<$ 0.001). In contrast, the bystander cells did not show significant variation in IL-12 between $L d W T$ and $L d C e n^{-/-}$infections at $12 \mathrm{~h}$ point (Figure $2 \mathrm{~F}$ ).

\section{Suppression of miR-21 Occurs in DCs Only Upon Live LdCen-/- Infection}

Our results indicated that infection with live virulent or live attenuated parasites results in distinctly altered miR-21 expression and impacts the innate and adaptive immunity in significant ways. This led to a hypothesis whether live attenuated parasites are necessary to suppress the miR-21 expression or similar effect could also be achieved by a killed parasite. A killed attenuated parasite would be considered safer vaccine antigen compared to live attenuated parasite. To verify if expression of miR-21 in dendritic cells is dependent on infection with live $L_{d C e n}{ }^{-/-}$parasites, we infected mice with live $L d W T^{R F P}$ or $L d C e n^{-/-m C h e r r y}$ or killed LdCen $n^{-/-m C h e r r y}$ parasites and $24 \mathrm{~h}$ post infection, parasitized DCs were sort selected from spleen and lymph nodes (Figures 3A,B). In experiments with killed fluorescent $\mathrm{LdCen}^{-/}$parasites, since no replication of these parasites occurs in vivo, We have selected $24 \mathrm{~h}$ post infection to isolate parasitized DCs to assess the expression of miR-21. We did not observe any loss of fluorescence in killed $L d C e n^{-/-m C h e r r y}$ parasites due to the fixing process (Figure 3B, killed LdCen ${ }^{-/-m C h e r r y}$ panel). Expression of miR21 was measured by RT-PCR in cells sort selected based on $\mathrm{RFP} / \mathrm{mCherry}$ fluorescence. Results showed that only infection with viable $L d C e n^{-/-m C h e r r y}$ parasites induced a reduction in miR-21 expression compared to $L d W T^{R F P}$ infection (Figure 3C, $* * p<0.01)$. No significant reduction in miR-21 occurred in the cells infected with killed $L d C e n^{-/-m C h e r r y}$ parasites compared to $L d W T^{R F P}$ infection (Figure $3 \mathrm{C}$ ). These results suggest that alteration of miR-21 expression is dependent on presence of live parasite rather than killed parasite antigen.

\section{Blocking of LdWT Infection Induced miR-21 Restores CD4+ T Cell Proliferation}

To determine if miR-21 mediated IL-12 regulation occurs in vivo, mice were infected with $L d W T$ or $L d C e n^{-/}$parasites and treated with LNA chemistry based anti-miR-21 oligonucleotides on days 0,2 , and 4 (Figure 4A). Splenic DCs from the infected mice were isolated 7 days post-infection and the expression of miR-21 and IL-12 was measured. Results showed that consistent with our previous studies, $L d C e n^{-/-}$infection induced reduced levels of miR-21 and correspondingly high levels of IL-12 compared to $L d W T$ infection (Figures $4 \mathbf{B}, \mathbf{C},{ }^{* *} p<0.01$, ${ }^{* * *} p<$ $0.001)$. Treatment with LNA resulted in a significant reduction of miR-21 in $L d W T$ infection (Figure 4B). Similar reduction was not evident in $\mathrm{LdCen}^{-/-}$infection presumably due to low induction of miR-21 following infection which was also observed in our in vitro studies (Figures $4 \mathrm{~B}, \mathrm{C}$ ). Correspondingly the IL12 expression was significantly higher in LNA treated $L d W T$ infection compared to $L d W T$ infected control (Figure 4C). Similar increment in the expression of IL-12 was not observed in 


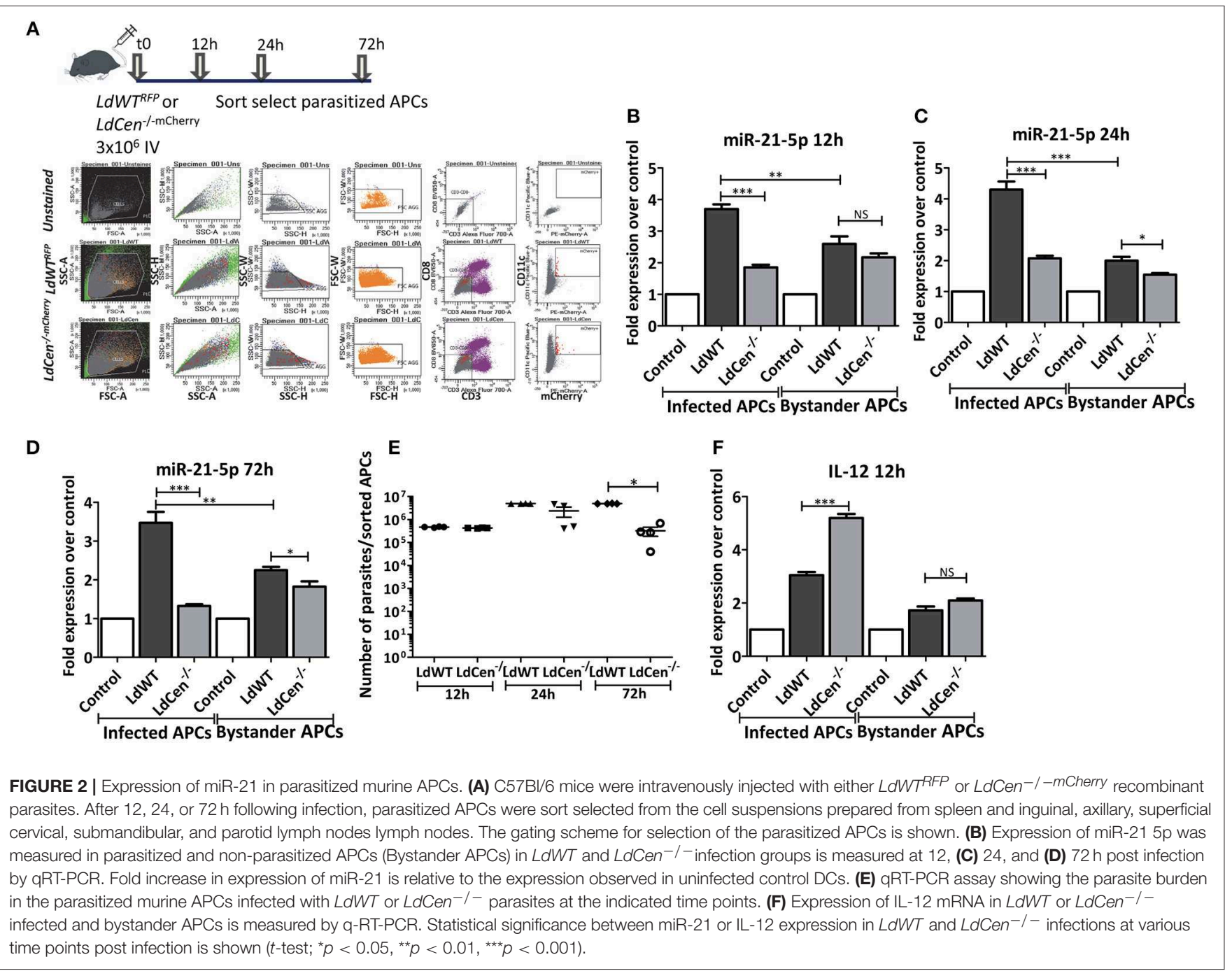

$\mathrm{LdCen}^{-/-}$upon LNA treatment since the background level of IL12 expression to begin with was higher in $\mathrm{LdCen}^{-/-}$compared to $L d W T$ infection (Figure 4C). To measure if the altered level of IL-12 in these groups impacts the adaptive immune responses, we infected the mice with $L d W T$ and $L d C e n^{-/-}$parasites secreting $\mathrm{CD}^{+}{ }^{+} \mathrm{T}$ cell specific $2 \mathrm{~W}$ peptide. Using tetramers against $2 \mathrm{~W}$ peptide, epitope specific $\mathrm{CD} 4^{+} \mathrm{T}$ cells were isolated and identified on flow cytometry (Figure 4D). Results showed that inhibition of miR-21 by LNA-oligonucleotides significantly increases the $\mathrm{CD} 4{ }^{+} \mathrm{CD} 44^{+} 2 \mathrm{~W}^{+} \mathrm{T}$ cell population compared to untreated $L d W T^{2 W}$ infection. Treatment with LNA had no effect in the $2 \mathrm{~W}$ specific CD4 ${ }^{+} \mathrm{T}$ cell population in $L d C e n^{-}-2 \mathrm{~W}$ infection (Figure $4 \mathrm{E},{ }^{*} p<0.05$ ). To test the proliferation of $2 \mathrm{~W}$ specific population following infection with $L d W T$ or $L d C e n^{-/-}$ parasite infection, IL-2R expression was used as a marker. $\mathrm{LdCen}^{/-2 \mathrm{~W}}$ infection resulted in significantly higher IL-2 $\mathrm{R}^{+}$ $\mathrm{CD}^{+} \mathrm{T}$ cells as was observed in our previous studies (8). Consistent with the increased proliferation, IL-2R expression was also significantly higher in LNA treated $L d W T$ infection compared to untreated group (Figure $4 \mathrm{~F},{ }^{*} p<0.05$ ). Although proliferation of the $2 \mathrm{~W}$ specific $\mathrm{CD}^{+} \mathrm{T}$ cell population was observed in LNA treated $L d W T$ infection, expression of other markers of early memory such as IL-7R were absent in this population. In contrast, a significantly higher IL-7R $\mathrm{R}^{+} 2 \mathrm{~W}^{+} \mathrm{CD} 4^{+}$ T cell population was observed $\mathrm{LdCen}^{-/-}$infection similar to our previously published results (24) and no change in expression was observed upon LNA treatment (Figure 4G, ${ }^{*} p<0.05$ ). To measure if blocking miR-21 expression impacts the parasite proliferation, we measured the splenic parasite burden following treatment with LNA treatment. Splenic parasite burden 2 weeks after LNA treatment showed that blocking miR-21 expression significantly reduces the parasite burden in $L d W T$ infection (Figure $4 \mathbf{H},{ }^{*} p<0.05$ ).

\section{Exosomes Released From LdWT Infected DCs Contain High Levels of miR-21}

Recent studies showed that intracellular parasites utilize exosome mediated signaling with the host immune cells to alter host immunity (25-27) Further, in the early time points after infection, we observed that miR-21 levels were altered in 


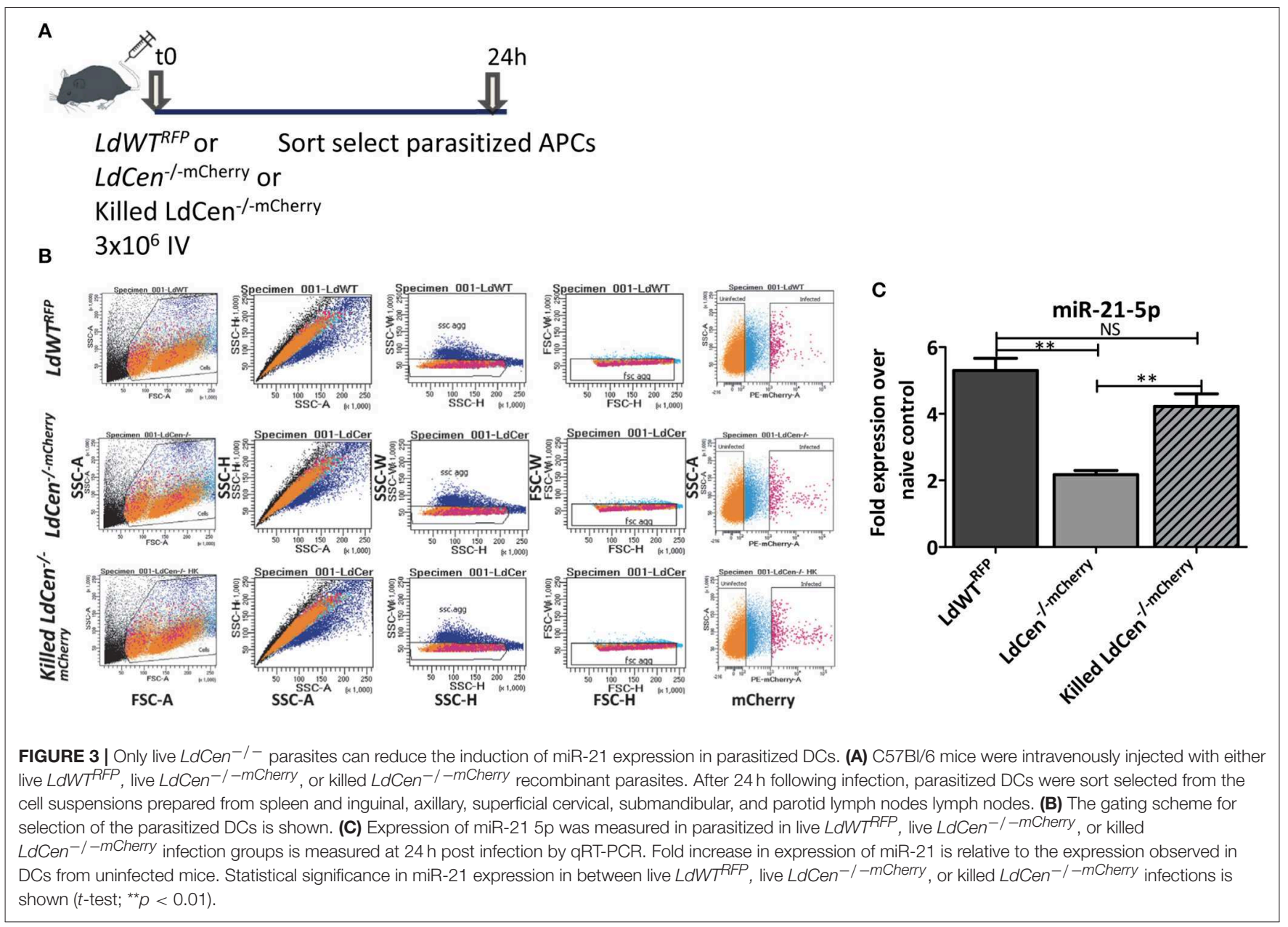

bystander cells (RFP/mCherry negative population) in addition to the parasitized cells (RFP/mCherry positive population, Figures 2B-D). Consistent with this observation, at $12 \mathrm{~h}$ post infection, IL-12 levels were also significantly higher in $L d C e n^{-/-m C h e r r y}$ parasitized cells compared to $L d W T^{R F P}$ infection. To test if miR-21 expression has any role in mediating systemic effects, we infected murine BMDCs in vitro with $L d W T$ or $\mathrm{LdCen}^{-/-}$parasites and isolated exosomes from the culture supernatants. RT-PCR results from the exosomes precipitated from the supernatants of the infected DC cultures showed that levels of miR-21 levels were significantly higher in $L d W T$ infection compared to $\mathrm{LdCen}^{-/-}$(Figure 5A). In contrast, very little miR-21 was detectable above the basal level expression observed in exosomes from uninfected DCs (Figure 5A). Since our previous results established the role of miR-21 in IL-12 mediated CD4 ${ }^{+} \mathrm{T}$ cell proliferation, to confirm whether miR-21 enriched exosomes can affect the priming and proliferation of $\mathrm{CD}^{+} \mathrm{T}$ cells, we performed $\mathrm{T}$ cell coculture experiments. To test whether exosomes enriched in miR-21 could have bystander effects, BMDCs infected with $\mathrm{LdCen}{ }^{-/-}$were cultured in presence of CFSE labeled OT-II cells. Previous studies have shown that $\mathrm{LdCen}^{-/-}$infection of BMDCs results in robust proliferation of OT-II $\mathrm{CD} 4^{+} \mathrm{T}$ cells (13). We performed similar OT-II CD4 ${ }^{+} \mathrm{T}$ cell co-culture experiments in presence of exosomes enriched independently from uninfected or $L d W T$ infected or $L d C \mathrm{Cn}^{-/-}$infected BMDCs. To test the specificity of exosomal miR-21, we performed the coculture experiments with exosomes purified from both $L d W T$ and $\mathrm{LdCen}^{-/-}$infection without and with treatment of LNAanti-miR-21 oligonucleotides (Figure 5B). Dilution of CFSE staining 5 days after co-culture was measured by flow cytometric analysis as a measure of $\mathrm{T}$ cell proliferation (Figure 5C). Results showed that no difference in the proliferation occurred in presence of exosomes derived from uninfected DCs compared to no exosome control (Figures $\mathbf{5 C}-\mathbf{G}$ ). However, in presence of $L d W T$ infection derived exosomes there was a significant reduction in the proliferation compared to no exosome control or in presence of exosomes derived from uninfected DCs suggesting that miR-21 enriched exosomes from $L d W T$ infection exert inhibitory effects (Figure 5G, ${ }^{* *} p<0.01$ ). Inhibition of miR-21 partially restored the OT-II cell proliferation in $L d W T$ infection (Figures 5E,G, ${ }^{*} p<0.05$ ). No significant difference in $\mathrm{CFSE}^{+} \mathrm{CD}^{+} \mathrm{T}$ cell proliferation was observed in presence of treated and untreated $\mathrm{LdCen}^{-/-}$infection derived exosomes (Figures 5F,G). Inhibition of miR-21 in $\mathrm{LdCen}^{-/-}$ derived exosomes did not affect the proliferation relative to 


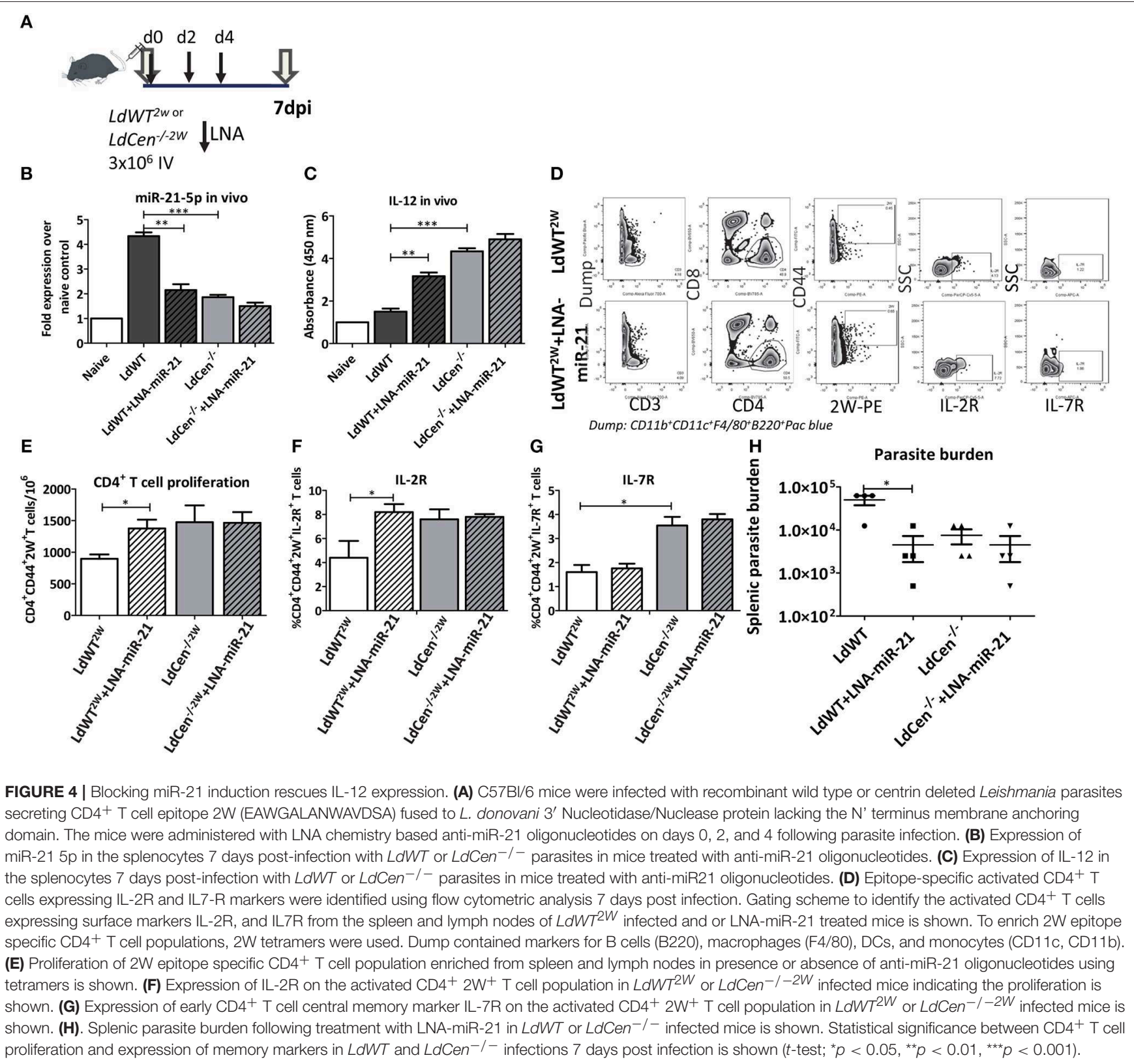

no exosome, and null exosome controls (Figure 5G). These results suggest that in addition to the effects observed in the infected cells, miR-21 in the exosomes exerts strong effect on the proliferation of $\mathrm{T}$ cells possibly through regulation of IL12 levels.

\section{LdCen-/- Infection Induced miR-21 Expression Alteration in Macrophages Derived From Healthy Human Blood Donors}

To confirm if miR-21 mediated regulation of IL-12 expression observed in murine studies is also evident in human macrophages, elutriated monocytes from US blood donors were differentiated into macrophages in vitro. These macrophages were infected with either $L d W T$ or $L d C e n^{-/-}$parasites and/or treated with LNA-anti-miR-21 oligonucleotides. RT-PCR experiments revealed that there was increase in miR-21-5p expression upon $L d W T$ infection compared to $\mathrm{LdCen}^{-/-}$ infection and concomitant reduction in IL-12 levels in $L d W T$ infection and increase in $\mathrm{LdCen}^{-/-}$infection (Figures 6A,B, $\left.{ }^{*} p<0.05,{ }^{* *} p<0.01,{ }^{* * *} p<0.001\right)$ similar to that observed in murine studies (Figure 2). Blocking of miR-21 resulted in a significant decrease in miR-21 levels and increase in IL-12 expression in $L d W T$ infected macrophages (Figure 6B, $\left.{ }^{*} p<0.05\right)$. As was observed previously, such inhibition did 


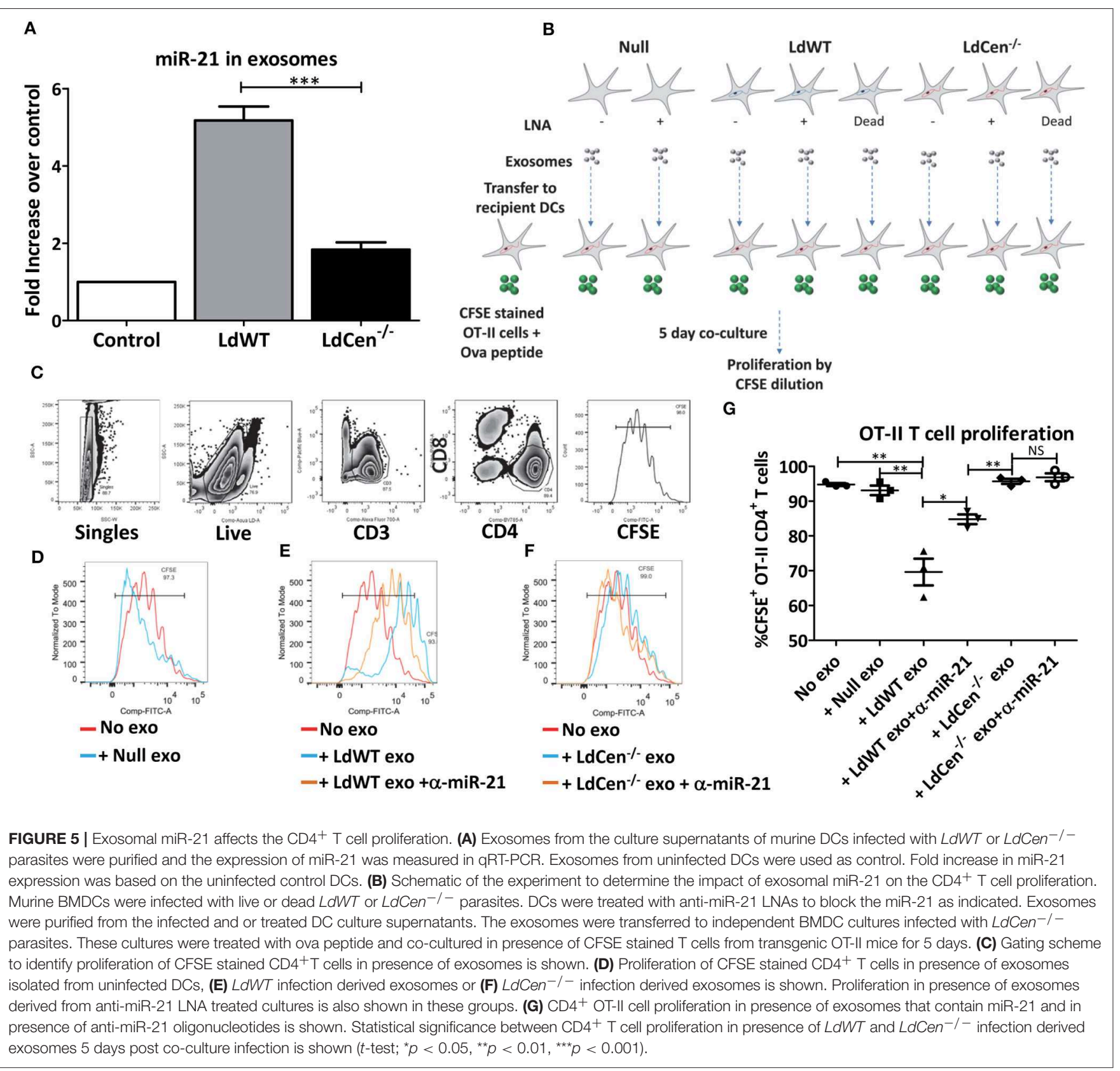

not result in an increased IL-12 expression in $\mathrm{LdCen}^{-/-}$ infection (Figure 6B). RT-PCR assay to measure the Leishmania minicircle DNA showed a comparable parasite infection in the infected macrophages suggesting that the observed differences in miR-21 and IL-12 levels between $L d W T$ and $\mathrm{LdCen}^{-/}$are not due to variation in the parasite infection level (Figure 6C). A pairwise comparison of miR-21 expression in the donor macrophages showed that in both $L d W T$ and $L_{d C e n}{ }^{-/}$infections inhibition reduced the miR-21 expression (Figures 6D,E, ${ }^{* *} p<0.01$ ). Taken together these data suggest that suppression of miR-21 can be a potential biomarker for $\mathrm{LdCen}^{-/-}$induced immunity.

\section{DISCUSSION}

Live attenuated Leishmania parasites are investigated as potential candidate vaccines. There is a broader understanding of the key determinants of protective immunity necessary in a candidate vaccine (23). Several studies have shown the importance of IL12 in both cutaneous and visceral leishmaniasis $(23,28-31)$. Protective immunity to Leishmania is mediated by a strong Th1 response that is critically dependent on IL-12 production by dendritic cells $(32,33)$. Production of IL-12 is a complex process that is regulated by multiple transcription factors that results in the production of two subunits IL-12p35 and IL-12p40 that 


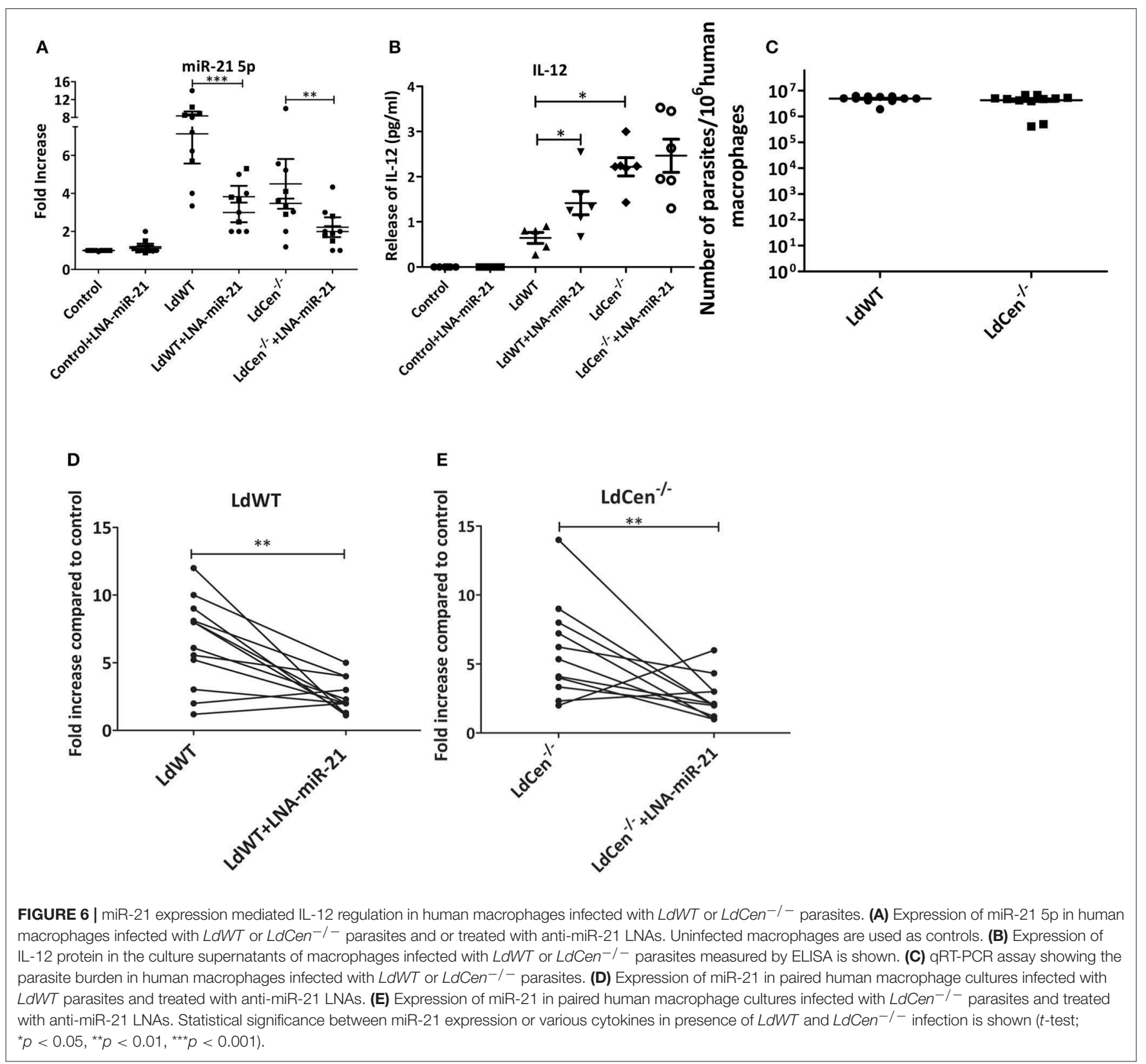

form the functional heterodimer IL-12p70 secreted by immune cells. Therefore, the secretion of IL-12 depends on the availability of individual IL-12p35 and IL-12p40 subunits (34). The p35 and p40 subunits of IL-12 are encoded in distinct loci in the human genome (35). Whereas, the smaller p35 subunit in produced constitutively in majority of cell types, $\mathrm{p} 40$ subunit is transcribed more often in the context of infection or in presence of an inflammatory signal (36). Both subunits however share promoter motifs that define the transcription factor binding sites, suggesting an overall common regulatory mechanisms in producing IL-12p70 (34).

Independent studies have shown that several distinct mechanisms determine the expression of IL-12 following
Leishmania infection. Infection with $L$. donovani has been shown to induce a differential expression pattern for IL-12associated genes, including NF- $\mathrm{BB}$ factor and IFN- $\gamma$ associated pathways (37). During early infection, L. major-infected DCs exhibited a distinct type-I IFN-associated transcriptomic signature, including the upregulation of IRF2, IRF9, STAT1/2, and IFNAR (38). Differences in L. major and L. donovani infections with respect to expression of IRF2, IRF7, and IFIT5 was also reported analogous to the IL-12p40 gene expression elicited by these two parasite species (38). Similarly, in L. major infections, ligation of CD40-CD40L, and macrophage antigen-1 (Mac-1)-CD40L interaction have been shown to induce IL12 production (39). In this study we explored an additional 
mechanism of regulation of IL-12 by miR-21 that is used by the Leishmania parasite.

Previous studies in allergic airway inflammation have shown that the microRNA miR-21 targets the $3^{\prime}$ UTR of the IL-12 p35 and expression of miR-21 was shown to result in the loss of I-12p35 transcript (22). Studies in miR-21-/- mice using Ova peptide stimulation showed dysregulation of IL-12/IFN- $\gamma$ pathway upon transcriptome analysis, that resulted in altered $\mathrm{T}$ cell polarization implying the role of miR-21 in regulating the expression of IL-12p35 (21). Our results first showing the upregulation of miR-21 in virulent $L$. donovani infection compared to $\mathrm{LdCen}^{-/-}$infection represents a novel mechanism by which IL-12 production is regulated in the parasitic infections. Stimulation of IL-12 production upon inhibition of miR21 both in vitro and in vivo shows the specificity of the miR-21 and IL-12 production. Further, lack of induction of miR-21 in $\mathrm{LdCen}^{-/-}$infection compared to LdWT infection may represent an immunological mechanism orchestrated by $\mathrm{LdCen}{ }^{-/-}$parasites that results in increased IL-12 production. Early heightened induction of IL-12 has been shown to be required for the induction of protective immunity in several Leishmania studies $(28,40)$. Thus, the IL-12 expression observed in $\mathrm{LdCen}^{-/-}$parasite infection suggests that miR-21 mediated regulation might be a key step in promoting strong protective immune response.

In addition to altering the miR-21 expression in the infected cells, our results also showed that exosomes released from $L d \mathrm{Cen}^{-/-}$infection contained reduced miR-21 levels compared to $L d W T$ infection, representing a systemic effect propagated by the exosomes derived from $\mathrm{LdCen}{ }^{-/-}$infected cells. Our results on the abundance of miR-21 in the exosomes secreted by the $L d W T$ infected DCs exerting anti-inflammatory effects show that the induction of miR-21 can lead to systemic effects by contact-independent mechanisms. Consistent with this result, bystander APCs with $L d W T$ infection identified in our in vivo experiments also showed reduced IL-12 in our experiments at early time points indicating that exosome mediated miR-21 may be involved in such reduction. In other studies plasma exosome miR-21 is known to indicate breast cancer (41). Human macrophages infected with BCG also secrete exosomes containing miR-21 (42). Similar effects mediated by exosomes on IL-12 and TNF were reported previously (43). Our results with exosomes derived from $L d W T$ infected DCs on the $\mathrm{T}$ cell proliferation suggest that miR-21 enriched in the exosomes could be a principal mechanism by which IL12 regulation could be achieved overall. Our study shows that redundant mechanisms might exist to achieve that outcome including miR-21 mediated degradation of IL-12 mRNA. The exosome mediated IL-12 regulation is likely to occur through miR-21 mediated effects. This argument is supported by our findings that inhibition of miR-21 by anti-sense oligos in our in vitro experiments and by LNA based inhibitors in the in vivo experiments showed a significant induction of IL-12. The central question as to what causes miR-21 expression to be subdued in $L d \mathrm{Cen}^{-/-}$parasite infection relative to $L d W T$ infection remains to be investigated. The attenuated virulence of $\mathrm{LdCen}^{-/-}$parasites might lead to such overall effect. This hypothesis is supported by our results with killed $\mathrm{LdCen}^{-/-}$ that failed to suppress miR-21 induction suggesting that factors regulating miR-21 suppression are produced only by the live $\mathrm{LdCen}^{-1-}$ parasites.

In addition to IL-12, miR-21 is shown to target PDCD4 and IL10 (44). Quantitative RT-PCR results with $L d W T$ and $\mathrm{LdCen}^{-/-}$infected murine DCS showed no significant difference in the PDCD4 levels (data not shown). Further, our results showed that IL-10 levels were not significantly altered between $L d W T$ and $\mathrm{LdCen}^{-/-}$infections upon blocking miR21 indicating that specifically IL-12 regulation through miR-21 occurred in $L d W T$ and $L d C e n^{-/-}$parasite infections. Additional role for exosomal miR-21 has been described in inducing alternative activation of macrophages (M2 type) (45). As the live attenuated Leishmania parasites such as $\mathrm{LdCen}^{-1-}$ are tested in pre-clinical studies as candidate vaccines, our studies identify a key characteristic that may indicate a critical immune regulatory mechanism that is necessary for protective immunity. In addition to CD40 mediated IL-12 expression observed in our previous studies (13), our current study represents a novel mechanism by which IL-12 expression is regulated. Previous studies comparing the expression of miR-21 showed that wild type $L$. donovani infection induces higher levels compared to $L$ major infection suggesting that differences might exist between different species of Leishmania (46). Our results showed that in addition to miR-21, miR-3651, and miR-3679 were also enriched in $L d W T$ compared to $\mathrm{LdCen}^{-/-}$infection. Although miR-3651 and miR3679 are reported in the literature as prognostic biomarkers for myesthnia gravis, sepsis or squamous cell carcinoma (47-50) their role in gene expression regulation has not been studied.

Taken together, our results show that miR21 is a key determinant of IL-12 production following $L$. donovani infection and that live attenuated parasite infection such as $\mathrm{LdCen}^{-/-}$ causing suppression of miR-21 is a novel finding and suggests that infection with attenuated parasites produces controlled inflammation thus leading to protective immunity.

\section{MATERIALS AND METHODS}

\section{Parasites and Animals}

Five to six weeks old female $\mathrm{C} 57 \mathrm{Bl} / 6$ mice were obtained from the Charles River Laboratories. The animal procedures and experiments described were approved by FDA's Animal Care and Use Committee (Study 1995-26, updated and re-approved $8 / 18 / 2016$ ). The animal program is fully compliant with the US PHS Policy on Humane Care and Use of Laboratory Animals and standards for full accreditation by AAALAC International. The wild type $L$. donovani $(L d W T)(\mathrm{MHOM} / \mathrm{SD} / 62 / 1 \mathrm{~S})$ maintained in golden Syrian hamsters and centrin gene deleted $\left(\mathrm{LdCen}^{-/}\right)$ line of $L$. donovani were used in the experiments. Red fluorescent protein expressing $L d W T^{R F P}$ and mCherry protein expressing $L d \mathrm{Cen}^{-/-}\left(\mathrm{LdCen}^{-/-\mathrm{mCherry}}\right)$ parasites were used to sort select infected DCs from C57Bl/6 mice. $L d W T$ and $L d \mathrm{Cen}^{-/-}$ parasites secreting $2 \mathrm{~W}$ epitope (EAWGALANWAVDSA) fused to $L$. donovani $3^{\prime}$ Nucleotidase/Nuclease protein lacking the $\mathrm{N}^{\prime}$ terminus membrane anchoring domain, were used to enrich epitope specific $\mathrm{CD} 4^{+} \mathrm{T}$ cells. The recombinant $L d W T$ 
and $\mathrm{LdCen}^{-/-}$parasites expressing fluorescent or chimeric proteins have been described previously $(11,24)$. The $2 \mathrm{~W}$ PE tetramers (2W1S:I-A ${ }^{\mathrm{b}}$-streptavidin-phycoerythrin) used to enrich the CD4T cells were obtained from NIH tetramer core facility in Emory Vaccine Center, Atlanta, GA.

\section{Human Monocytes}

Human elutriated monocytes obtained from NIH blood bank from healthy US blood donors. Only monocytes that tested CMV negative were used in this study. Monocytes were resuspended at $1.8 \times 10^{5}$ cells $/ \mathrm{ml}$ in RPMI medium containing $10 \% \mathrm{FBS}$ and human macrophage colony stimulating factor $(20 \mathrm{ng} / \mathrm{ml}$, ProSpec), plated in a volume of $0.5 \mathrm{ml}$ in eight-chamber Lab-Tek tissue culture slides (Miles Laboratories) and incubated for 7 days for differentiation into macrophages.

\section{Macrophage Infection}

The differentiated macrophages were infected with stationary phase $L d W T$ or $L d C e n^{-/-}$promastigotes (10:1 parasite-tomacrophage ratio). After incubation for $6 \mathrm{~h}$ at $37^{\circ} \mathrm{C}$ in $5 \% \mathrm{CO}_{2}$, the free extracellular parasites were removed by RPMI washes and the cultures were incubated in macrophage culture medium for an additional $24 \mathrm{~h}$. The culture medium was removed and total RNA was extracted from the infected macrophages using Purelink Ambion kit. RNAseq was performed at the core facility of Center for Biologics Evaluation and Research, FDA.

\section{In vitro Blocking of miR-21}

Dendritic cells were cultured in vitro from bone marrow progenitors. Bone marrow aspirates from $\mathrm{C} 57 \mathrm{Bl} / 6$ mice were cultured with complete RPMI medium supplemented with $10 \%$ (v/v) fetal bovine serum (FBS) and $20 \mathrm{ng} / \mathrm{mL}$ murine GM-CSF (Peprotech) and murine IL-4 (Peprotech) for 7 days at $37^{\circ} \mathrm{C}$ and $5 \% \mathrm{CO}_{2}$ to obtain CD11c ${ }^{+}$DCs. DCs were infected with either $L d W T$ or $L d C e n^{-/-}$parasites for $6 \mathrm{~h}$ (10:1 parasite to DC ratio). Free extracellular parasites were removed by extensive washes with complete RPMI. Infected DCs were incubated with antimiR-21 oligos packaged in mouse DC derived exosomes (XMIR21, System Biosciences) for $24 \mathrm{~h}$. Total RNA was isolated from the infected XMIR-21 treated DCs and used in RT-PCR assays.

\section{Expression of miR-21 in vivo in LdWT or LdCen $^{-/-}$Infected DCs}

$\mathrm{C} 57 \mathrm{Bl} / 6$ mice were infected intravenously with fluorescent live or killed $L d W T^{R F P}$ or $L d C e n^{-/--m C h e r r y}$ parasites. Spleens were collected from the mice $24 \mathrm{~h}$ after the infection, homogenized and single cell suspensions were prepared after ACK lysis. DCs were isolated from the cell suspension using Pan-Dendritic cell isolation kit (Miltenyi Biotec). Parasitized DCs were sort selected based on the RFP or mCherry fluorescence (FACSAria II, BD). RNA isolated from the parasitized DCs was used in a qRT-PCR to detect the expression of miR-21.

\section{RT-PCR}

Total RNA was extracted from the parasitized DCs using RNAqueous Microkit (Ambion). Total RNA was reverse transcribed into cDNA using random hexamers by a highcapacity cDNA reverse transcription kit (Applied Biosystems). Gene expressions were determined by TaqManGene Expression Master Mix and pre-made TaqMan Gene Expression assays (Applied Biosystems) using a CFX96 Touch real-time system (Bio-Rad). The data were analyzed with CFX Manager software. The TaqMan Gene Expression Assay ID (Applied Biosystems) of different primers used was as follows: miR-21 (Mm00434174); and GAPDH (Mm99999915). Expression values were determined by the $2{ }_{-} \Delta \Delta \mathrm{Ct}$ method where samples were normalized to GAPDH expression.

\section{CD4 ${ }^{+}$T Cell Proliferation}

$\mathrm{CD}^{+} \mathrm{T}$ cell proliferation was measured in mice infected with $L d W T$ or $L d C e n^{-/-}$followed by treatment with miR-21 inhibitor LNAs $(10 \mu \mathrm{g} / \mathrm{dose})$. At each experimental time point post infection spleens, inguinal, axillary, cervical, submandibular, and parotid lymph nodes were collected. Single cell suspensions from these organs were used to enrich for $2 \mathrm{~W}$ specific $\mathrm{CD} 4^{+} \mathrm{T}$ cells using tetramer reagents on LS columns (Miltenyi). Enriched cells were labeled and analyzed using flow cytometry.

\section{$\mathrm{CD}^{+} \mathrm{T}$ Cell Proliferation in Presence of Exosomes}

Bone marrow aspirates from $\mathrm{C} 57 \mathrm{Bl} / 6$ mice were cultured with complete RPMI medium supplemented with $10 \%(\mathrm{v} / \mathrm{v})$ fetal bovine serum (FBS) and $20 \mathrm{ng} / \mathrm{mL}$ murine GM-CSF and IL4 (Peprotech) for 7 days at $37^{\circ} \mathrm{C}$ and $5 \% \mathrm{CO}_{2}$ to obtain $\mathrm{CD}_{11 c^{+}}$DCs. BMDCs were infected with either $L d W T$ or $\mathrm{LdCen}^{-/-}$parasites for $6 \mathrm{~h}$ (10:1 parasite to DC ratio). The parasite infections were performed either in presence or absence of anti-miR-21 oligonucleotides for $24 \mathrm{~h}$ in complete RPMI medium containing 10\% exosome-free FBS (System Biosciences). The exosomes released by the uninfected, parasite infected and/or anti-miR-21 treated BMDC cultures were pelleted using ExoQuickTC reagent (System Biosciences). In parallel, another set of BMDC cultures were pulsed with $2 \mu \mathrm{g} / \mathrm{ml}$ OVA peptide (323-339, AnaSpec) for $4 \mathrm{~h}$ and infected with $\mathrm{LdCen}^{-/-}$ parasites. T cells isolated from a transgenic OT-II mouse using Pan-T cell isolation kit (Miltenyi Biotec) were labeled with CFSE and co-cultured with Ova pulsed, $L d C e n^{-/-}$infected BMDCs above in presence or absence of exosomes isolated as described above. Flow cytometric analysis was performed to measure the proliferation of CFSE labeled OT-II T cells after 5 days of coculture in presence or absence of exosomes. Cells were blocked at $4{ }^{\circ} \mathrm{C}$ with rat anti-mouse $\mathrm{CD} 16 / 32$ and stained with surface markers on ice with anti-B220, anti-CD11b, anti-CD11c, and anti-F4/80 all conjugated with eFluor 450; Alexa Flour 700-antiCD3, BV-785 anti-CD4, and BV-650 anti-CD8 $\alpha$. Live cells were selected from Live/dead aqua staining. Cells were then analyzed on an LSR Fortessa (Becton Dickinson). Data were analyzed with FlowJo software v10 (TreeStar).

\section{Flow Cytometry}

Tetramer staining was performed following the published protocol (24). Single cell suspensions were prepared from spleens and lymph nodes isolated from the infected mice. Cell 
suspensions were treated with $3 \mathrm{ml}$ of ACK lysis buffer (Lonza) for $5 \mathrm{~min}$ at room temperature. Cells were stained with $2 \mathrm{~W}$-PE tetramers for $1 \mathrm{~h}$ in the dark at room temperature. The tetramer coated cells were labeled with anti-PE magnetic beads for $30 \mathrm{~min}$ on ice. $2 \mathrm{~W}$ epitope specific $\mathrm{CD}^{+} \mathrm{T}$ cells were enriched on MACS LS magnetic columns. Cells were blocked at $4^{\circ} \mathrm{C}$ with rat anti-mouse CD16/32 and stained with surface markers on ice with anti-B220 (eBioscience, Clone: RA3-6B2, Cat\# 480452-82), anti-CD11b (eBioscience, Clone: M1/70, Cat\# 480112-82), anti-CD11c (eBioscience, Clone:BM8, Cat\# 48-011482), and anti-F4/80 (eBioscience, Clone:BM8, Cat\# 48-480182) all conjugated with eFluor 450 (Dump); Alexa Flour 700anti-CD3 (Biolegend, Clone: H57-597, Cat\# 109224), BV-785 anti-CD4 (Biolegend, Clone:RM4-5, Cat\# 100552), BV-650 antiCD8 $\alpha$ (Biolegend, Clone: 53-6.7, Cat\# 100742), FITC-anti-CD44 (Biolegend, Clone:IM7, Cat\# 103006), PerCP-Cy5.5 CD25 (BD, Clone: PC61, Cat\# 563866), BV-605 anti-CD62L(eBioscience, Clone:MEL-14, Cat\# 83-0621-42), APC anti-IL7R (eBioscience, Clone:A7R34, Cat\# 50-1271-82). Live cells were selected from Live/dead aqua staining. Cells were then analyzed on an LSR Fortessa (Becton Dickinson). Data were analyzed with FlowJo software v10 (TreeStar).

\section{ELISA to Measure Murine IL-12, TNF, and IL-10}

Murine BMDCs were prepared as described (13) and were infected with $L d W T$ or $L d C e n^{-/-}$parasites with or without LNA treatment. The culture supernatants were analyzed by ELISA for indicated cytokines. The conditioned media of DC cultures were assayed for mouse cytokines via sandwich ELISA kit (eBioscience, IFN, IL-10, TNF, and IL-12). The assay was performed according to the manufacturer's instructions.

\section{Parasite Load Determination by Quantitative PCR}

The parasite load was determined in the infected dendritic cells and human macrophages as previously described (51). Briefly, infected DCs/infected human macrophage samples were lysed for DNA purification by using DNeasy Blood \& Tissue kits (Qiagen). Seventy nanograms of sample DNA was used as a template in a Taqman-based quantitative PCR. The target DNA was amplified from a kinetoplast minicircle DNA of the parasite using the following sequence of primers: Leishmania forward primer 5'- CTATTTTACACCAACCCCCAGT-3' Leishmania reverse primer $5^{\prime}$-GGGTAGGGGCGTTCTGCGAAA-3' with the addition of a fluorescent probe 5'-RAAARKKVRTRCA GAAAYCCCGT-3' for detection. A Black Hole Quencher moiety was coupled to the $3^{\prime}$ end and Calfluor Red was coupled to a C6 linker at the $5^{\prime}$ end. The fluorescent Leishmania probe (5'-RAAARKKVRTRCAGAAAYCCCGT-3') was added to the reaction mixture at a final concentration of $1.5 \mathrm{pmols} / \mu \mathrm{l}$. Cycling parameters were as follows: preheat at $95^{\circ} \mathrm{C}$ for $180 \mathrm{~s}$ and then 40 two-step cycles of $95^{\circ} \mathrm{C}$ for $10 \mathrm{~s}$ and $55^{\circ} \mathrm{C}$ for $30 \mathrm{~s}$. To determine the number of Leishmania cells that were represented by a given cycle threshold (Ct) value, a standard curve was constructed by purification of DNA from naïve mice DCs/elutriated human macrophages spiked with a known number of parasites.

\section{Statistical Analysis}

Statistical analysis of differences between mean values of groups was determined by parametric unpaired two-tailed Student $t$-test and non-parametric Mann-Whitney test using GraphPad Prism 5.0 software. A $p<0.05$ was considered significant.

\section{DATA AVAILABILITY STATEMENT}

The datasets generated for this study are available on request to the corresponding author.

\section{ETHICS STATEMENT}

The animal study was reviewed and approved by FDA's Animal Care and Use Committee.

\section{AUTHOR CONTRIBUTIONS}

SG and HN conceived the project. SG, AS, PB, and NI performed the experiments. SG, PB, SM, and HN analyzed the data. SG, PB, and $\mathrm{HN}$ wrote the manuscript.

\section{FUNDING}

This work was supported by the intramural funds of the Center for Biologics Evaluation and Research, US Food and Drug Administration. The findings of this study are an informal communication and represent the authors' own best judgments. These comments do not bind or obligate the Food and Drug Administration.

\section{ACKNOWLEDGMENTS}

2W1S:I-Ab-streptavidin-phycoerythrin (2W-PE) tetramers were obtained from NIH tetramer core facility at Emory University, Atlanta, GA, USA. The reagents and the protocol for qRT-PCR assay to measure parasite burden are provided by Drs. Robert Duncan and Ranadhir Dey.

\section{SUPPLEMENTARY MATERIAL}

The Supplementary Material for this article can be found online at: https://www.frontiersin.org/articles/10.3389/fimmu. 2019.02273/full\#supplementary-material

Supplementary Figure 1 | Parasite infectivity of human macrophages. Human macrophages from four independent blood donors were infected with stationary phase $L d W T$ or $L d C e n^{-/-}$parasite cultures. Twenty four hours post infection, the infected macrophages were fixed and stained with diff-quik staining reagents. The percentage of infected macrophages were counted in triplicate and expressed as $\%$ infected macrophages.

Supplementary Figure 2 | Secretion of IL-10 and IFN following blocking of miR-21. (A) Expression of IL-10 protein in the culture supernatants of macrophages infected with $L d W T$ or $L d C e n^{-/-}$parasites measured by ELISA is shown. (B) Expression of IFN- $\gamma$ protein in the culture supernatants of macrophages infected with $L d W T$ or $L d C e n^{-/-}$parasites measured by ELISA is shown.

Supplementary Table 1 | Enrichment of microRNAs and non-coding RNAs in Leishmania infected human macrophages. Human macrophages from four independent blood donors were infected with stationary phase $L d W T$ or 
$\mathrm{LdCen}^{-/-}$parasite cultures. RNA was isolated from the infected macrophages $24 \mathrm{~h}$ post infection and subjected to small RNAseq reaction. Identities of the small RNAs enriched in uninfected control relative to $\mathrm{LdCen}^{-/}$- infection (Up UI vs. Cen

\section{REFERENCES}

1. Singh OP, Hasker E, Boelaert M, Sundar S. Elimination of visceral leishmaniasis on the Indian subcontinent. Lancet Infect Dis. (2016) 16:e304-9. doi: 10.1016/S1473-3099(16)30140-2

2. Burza S, Croft SL, Boelaert M. Leishmaniasis. Lancet. (2018) 392:951-70. doi: 10.1016/S0140-6736(18)31204-2

3. Engwerda CR, Matlashewski G. Development of Leishmania vaccines in the era of visceral leishmaniasis elimination. Trans $R$ Soc Trop Med Hyg. (2015) 109:423-4. doi: 10.1093/trstmh/trv039

4. Hasker E, Singh SP, Malaviya P, Picado A, Gidwani K, Singh RP, et al. Visceral leishmaniasis in rural bihar, India. Emerg Infect Dis. (2012) 18:1662-4. doi: $10.3201 /$ eid1810.111083

5. Mcilwee BE, Weis SE, Hosler GA. Incidence of endemic human cutaneous leishmaniasis in the United States. JAMA Dermatol. (2018) 154:1032-9. doi: 10.1001/jamadermatol.2018.2133

6. Schaut RG, Robles-Murguia M, Juelsgaard R, Esch KJ, Bartholomay LC, Ramalho-Ortigao M, et al. Vectorborne transmission of Leishmania infantum from Hounds, United States. Emerg Infect Dis. (2015) 21:2209-12. doi: 10.3201/eid2112.141167

7. Selvapandiyan A, Debrabant A, Duncan R, Muller J, Salotra P, Sreenivas G, et al. Centrin gene disruption impairs stage-specific basal body duplication and cell cycle progression in Leishmania. J Biol Chem. (2004) 279:25703-10. doi: 10.1074/jbc.M402794200

8. Selvapandiyan A, Dey R, Nylen S, Duncan R, Sacks D, Nakhasi HL. Intracellular replication-deficient Leishmania donovani induces long lasting protective immunity against visceral leishmaniasis. J Immunol. (2009) 183:1813-20. doi: 10.4049/jimmunol.0900276

9. Fiuza JA, Dey R, Davenport D, Abdeladhim M, Meneses C, Oliveira F, et al. Intradermal immunization of Leishmania donovani centrin knock-out parasites in combination with salivary protein LJM19 from sand fly vector induces a durable protective immune response in hamsters. PLoS Negl Trop Dis. (2016) 10:e0004322. doi: 10.1371/journal.pntd.0004322

10. Fiuza JA, Gannavaram S, Santiago Hda C, Selvapandiyan A, Souza DM, Passos LS, et al. Vaccination using live attenuated Leishmania donovani centrin deleted parasites induces protection in dogs against Leishmania infantum. Vaccine. (2015) 33:280-8. doi: 10.1016/j.vaccine.2014.11.039

11. Bhattacharya P, Dey R, Dagur PK, Kruhlak M, Ismail N, Debrabant A, et al. Genetically modified live attenuated Leishmania donovani parasites induce innate immunity through classical activation of macrophages that direct the Th1 response in mice. Infect Immun. (2015) 83:3800-15. doi: 10.1128/IAI.00184-15

12. Banerjee A, Bhattacharya P, Dagur PK, Karmakar S, Ismail N, Joshi $\mathrm{AB}$, et al. Live attenuated Leishmania donovani centrin gene-deleted parasites induce IL-23-dependent IL-17-protective immune response against visceral leishmaniasis in a murine model. J Immunol. (2018) 200:163-76. doi: 10.4049/jimmunol.1700674

13. Bhattacharya P, Dey R, Dagur PK, Joshi AB, Ismail N, Gannavaram S, et al. Live attenuated Leishmania donovani centrin knock out parasites generate non-inferior protective immune response in aged mice against visceral leishmaniasis. PLoS Negl Trop Dis. (2016) 10:e0004963. doi: 10.1371/journal.pntd.0004963

14. Ambros V. microRNAs: tiny regulators with great potential. Cell. (2001) 107:823-6. doi: 10.1016/S0092-8674(01)00616-X

15. He L, Hannon GJ. MicroRNAs: small RNAs with a big role in gene regulation. Nat Rev Genet. (2004) 5:522-31. doi: 10.1038/nrg1379

16. Filipowicz W, Bhattacharyya SN, Sonenberg N. Mechanisms of posttranscriptional regulation by microRNAs: are the answers in sight? Nat Rev Genet. (2008) 9:102-14. doi: 10.1038/nrg2290

17. Bushati N, Cohen SM. microRNA functions. Annu Rev Cell Dev Biol. (2007) 23:175-205. doi: 10.1146/annurev.cellbio.23.090506. 123406 tab in the excel sheets), and those enriched in LaWT infected macrophages relative to $L d C e n^{-/-}$infection (Up WT vs. Centrin tab in the excel sheets) are shown.
18. Drury RE, O'connor D, Pollard AJ. The clinical application of microRNAs in infectious disease. Front Immunol. (2017) 8:1182. doi: 10.3389/fimmu.2017.01182

19. Xiao C, Rajewsky K. MicroRNA control in the immune system: basic principles. Cell. (2009) 136:26-36. doi: 10.1016/j.cell.2008.12.027

20. Cullen BR. MicroRNAs as mediators of viral evasion of the immune system. Nat Immunol. (2013) 14:205-10. doi: 10.1038/ni.2537

21. Lu TX, Hartner J, Lim EJ, Fabry V, Mingler MK, Cole ET, et al. MicroRNA-21 limits in vivo immune response-mediated activation of the IL-12/IFN-gamma pathway, Th1 polarization, and the severity of delayed-type hypersensitivity. $J$ Immunol. (2011) 187:3362-73. doi: 10.4049/jimmunol.1101235

22. Lu TX, Munitz A, Rothenberg ME. MicroRNA-21 is up-regulated in allergic airway inflammation and regulates IL-12p35 expression. J Immunol. (2009) 182:4994-5002. doi: 10.4049/jimmunol.0803560

23. Kaye P, Scott P. Leishmaniasis: complexity at the host-pathogen interface. Nat Rev Microbiol. (2011) 9:604-15. doi: 10.1038/nrmicro2608

24. Ismail N, Kaul A, Bhattacharya P, Gannavaram S, Nakhasi HL. Immunization with live attenuated Leishmania donovani centrin(-/-) parasites is efficacious in asymptomatic infection. Front Immunol. (2017) 8:1788. doi: 10.3389/fimmu.2017.01788

25. Demarta-Gatsi C, Rivkin A, Di Bartolo V, Peronet R, Ding S, Commere $\mathrm{PH}$, et al. Histamine releasing factor and elongation factor 1 alpha secreted via malaria parasites extracellular vesicles promote immune evasion by inhibiting specific T cell responses. Cell Microbiol. (2019) 21:e13021. doi: $10.1111 / \mathrm{cmi} .13021$

26. Ofir-Birin Y, Regev-Rudzki N. Extracellular vesicles in parasite survival. Science. (2019) 363:817-8. doi: 10.1126/science.aau4666

27. Sisquella X, Ofir-Birin Y, Pimentel MA, Cheng L, Abou Karam P, Sampaio NG, et al. Malaria parasite DNA-harbouring vesicles activate cytosolic immune sensors. Nat Commun. (2017) 8:1985. doi: 10.1038/s41467-017-02083-1

28. Okwor I, Uzonna JE. Pathways leading to interleukin-12 production and protective immunity in cutaneous leishmaniasis. Cell Immunol. (2016) 309:32-6. doi: 10.1016/j.cellimm.2016.06.004

29. Liese J, Schleicher U, Bogdan C. The innate immune response against Leishmania parasites. Immunobiology. (2008) 213:377-87. doi: 10.1016/j.imbio.2007.12.005

30. Murray HW, Hariprashad J. Interleukin 12 is effective treatment for an established systemic intracellular infection: experimental visceral leishmaniasis. J Exp Med. (1995) 181:387-91. doi: 10.1084/jem.181.1.387

31. Ghalib HW, Whittle JA, Kubin M, Hashim FA, El-Hassan AM, Grabstein $\mathrm{KH}$, et al. IL-12 enhances Th1-type responses in human Leishmania donovani infections. J Immunol. (1995) 154:4623-9.

32. Scott P, Hunter CA. Dendritic cells and immunity to leishmaniasis and toxoplasmosis. Curr Opin Immunol. (2002) 14:466-70. doi: 10.1016/S0952-7915(02)00353-9

33. Von Stebut E. Immunology of cutaneous leishmaniasis: the role of mast cells, phagocytes and dendritic cells for protective immunity. Eur J Dermatol. (2007) 17:115-22. doi: 10.1684/ejd.2007.0122

34. Trinchieri G, Pflanz S, Kastelein RA. The IL-12 family of heterodimeric cytokines: new players in the regulation of $\mathrm{T}$ cell responses. Immunity. (2003) 19:641-4. doi: 10.1016/S1074-7613(03)00296-6

35. Gately MK, Renzetti LM, Magram J, Stern AS, Adorini L, Gubler U, et al. The interleukin-12/interleukin-12-receptor system: role in normal and pathologic immune responses. Annu Rev Immunol. (1998) 16:495-521. doi: 10.1146/annurev.immunol.16.1.495

36. Tone Y, Thompson SA, Babik JM, Nolan KF, Tone M, Raven C, et al. Structure and chromosomal location of the mouse interleukin-12 p35 and p40 subunit genes. Eur J Immunol. (1996) 26:1222-7. doi: 10.1002/eji.1830260606

37. Chaussabel D, Semnani RT, Mcdowell MA, Sacks D, Sher A, Nutman TB. Unique gene expression profiles of human macrophages and dendritic cells to phylogenetically distinct parasites. Blood. (2003) 102:672-81. doi: 10.1182/blood-2002-10-3232 
38. Favila MA, Geraci NS, Zeng E, Harker B, Condon D, Cotton RN, et al. Human dendritic cells exhibit a pronounced type I IFN signature following Leishmania major infection that is required for IL-12 induction. J Immunol. (2014) 192:5863-72. doi: 10.4049/jimmunol.1203230

39. Okwor I, Jia P, Uzonna JE. Interaction of macrophage antigen 1 and CD40 ligand leads to IL-12 production and resistance in CD40-deficient mice infected with Leishmania major. J Immunol. (2015) 195:3218-26. doi: 10.4049/jimmunol.1500922

40. Park AY, Scott P. Il-12: keeping cell-mediated immunity alive. Scand J Immunol. (2001) 53:529-32. doi: 10.1046/j.1365-3083.2001.00917.x

41. Hannafon BN, Trigoso YD, Calloway CL, Zhao YD, Lum DH, Welm AL, et al. Plasma exosome microRNAs are indicative of breast cancer. Breast Cancer Res. (2016) 18:90. doi: 10.1186/s13058-016-0753-x

42. Mortaz E, Alipoor SD, Tabarsi P, Adcock IM, Garssen J, Velayati AA. The analysis of exosomal micro-RNAs in peripheral blood mononuclear cell-derived macrophages after infection with bacillus Calmette-Guerin by RNA sequencing. Int J Mycobacteriol. (2016) 5(Suppl. 1):S184-5. doi: 10.1016/j.ijmyco.2016.09.045

43. Silverman JM, Clos J, Horakova E, Wang AY, Wiesgigl M, Kelly I, et al. Leishmania exosomes modulate innate and adaptive immune responses through effects on monocytes and dendritic cells. J Immunol. (2010) 185:5011-22. doi: 10.4049/jimmunol.1000541

44. Sheedy FJ, Palsson-Mcdermott E, Hennessy EJ, Martin C, O’leary JJ, Ruan Q, et al. Negative regulation of TLR4 via targeting of the proinflammatory tumor suppressor PDCD4 by the microRNA miR-21. Nat Immunol. (2010) 11:141-7. doi: $10.1038 /$ ni.1828

45. Ren W, Hou J, Yang C, Wang H, Wu S, Wu Y, et al. Extracellular vesicles secreted by hypoxia pre-challenged mesenchymal stem cells promote nonsmall cell lung cancer cell growth and mobility as well as macrophage M2 polarization via miR-21-5p delivery. J Exp Clin Cancer Res. (2019) 38:62. doi: 10.1186/s13046-019-1027-0

46. Geraci NS, Tan JC, Mcdowell MA. Characterization of microRNA expression profiles in Leishmania-infected human phagocytes. Parasite Immunol. (2015) 37:43-51. doi: 10.1111/pim.12156
47. Barzago C, Lum J, Cavalcante P, Srinivasan KG, Faggiani E, Camera G, et al. A novel infection- and inflammation-associated molecular signature in peripheral blood of myasthenia gravis patients. Immunobiology. (2016) 221:1227-36. doi: 10.1016/j.imbio.2016. 06.012

48. Chen J, Jiang S, Cao Y, Yang Y. Altered miRNAs expression profiles and modulation of immune response genes and proteins during neonatal sepsis. J Clin Immunol. (2014) 34:340-8. doi: 10.1007/s10875-0140004-9

49. Wang C, Guan S, Chen X, Liu B, Liu F, Han L, et al. Clinical potential of miR-3651 as a novel prognostic biomarker for esophageal squamous cell cancer. Biochem Biophys Res Commun. (2015) 465:30-4. doi: 10.1016/j.bbrc.2015.07.109

50. Ries J, Vairaktaris E, Agaimy A, Kintopp R, Baran C, Neukam FW, et al. miR-186, miR-3651 and miR-494: potential biomarkers for oral squamous cell carcinoma extracted from whole blood. Oncol Rep. (2014) 31:1429-36. doi: 10.3892/or.2014.2983

51. Selvapandiyan A, Duncan R, Mendez J, Kumar R, Salotra P, Cardo LJ, et al. A Leishmania minicircle DNA footprint assay for sensitive detection and rapid speciation of clinical isolates. Transfusion. (2008) 48:1787-98. doi: 10.1111/j.1537-2995.2008. 01798.x

Conflict of Interest: The authors declare that the research was conducted in the absence of any commercial or financial relationships that could be construed as a potential conflict of interest.

Copyright (c) 2019 Gannavaram, Bhattacharya, Siddiqui, Ismail, Madhavan and Nakhasi. This is an open-access article distributed under the terms of the Creative Commons Attribution License (CC BY). The use, distribution or reproduction in other forums is permitted, provided the original author(s) and the copyright owner(s) are credited and that the original publication in this journal is cited, in accordance with accepted academic practice. No use, distribution or reproduction is permitted which does not comply with these terms. 